\title{
Flame Retardant Concentrations Are Lower in College Spaces Meeting the New Furniture Flammability Standard TB117-2013
}

\author{
Kathryn M. Rodgers,* Adrian Covaci, Giulia Poma, Kristin Knox, Joseph G. Allen, Jose Cedeno-Laurent,
} Ruthann A. Rudel, and Robin E. Dodson

Cite This: Environ. Sci. Technol. Lett. 2020, 7, 833-839

Read Online

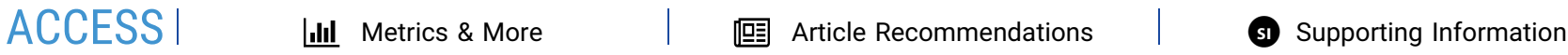

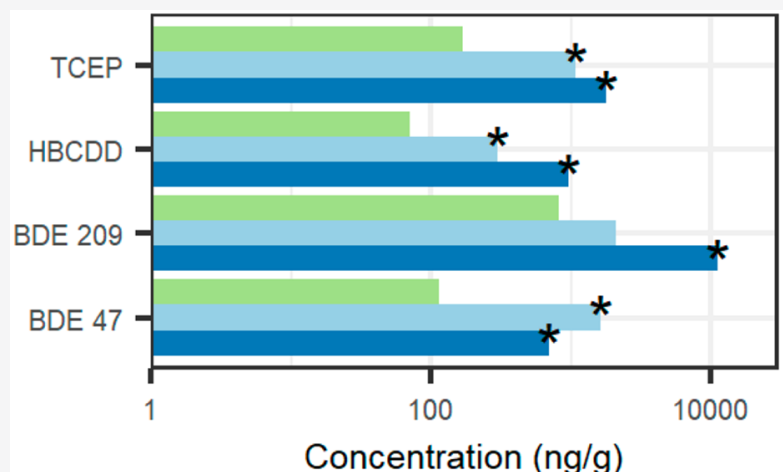

Flammability Standard

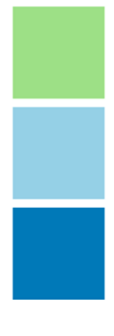

TB117-2013

TB117

TB133

ABSTRACT: California's updated furniture flammability standard, TB117-2013, can be met without the use of chemical flame retardants (FRs). FRs have been associated with neurological damage, reproductive toxicity, thyroid disease, and cancer. We collected dust from classrooms and other nonresidential spaces on four U.S. college campuses that met one of California's two older FR-reliant standards (TB117, TB133) or the newer TB117-2013. We hypothesized that spaces with TB117-2013-compliant furniture would have lower levels of FRs in dust. We detected all 43 targeted FRs, and FRs were detected in each of the 86 samples. We prioritized 14 FRs for statistical analysis based on their prevalence in dust and use in furniture and textiles. Concentrations of three polybrominated diphenyl ethers (PBDEs), hexabromocyclododecane (HBCDD), and tris(2-chloroethyl) phosphate (TCEP) were significantly lower in TB117-2013 spaces compared to spaces adhering to FR-reliant standards. Concentrations of BDE 209, decabromodiphenylethane (DBDPE), bis(2-ethylhexyl)-3,4,5,6-tetrabromophthalate (BEH-TEBP), hexabromobenzene (HBB), and tetrabromobisphenol A (TBBPA) were significantly lower in spaces meeting TB117-2013 compared to TB133 spaces. We report the highest dust levels of BDE 209, 2-ethylhexyl-2,3,4,5-tetrabromobenzoate (EH-TBB), DBDPE, and TCEP in the U.S. Spaces adhering to the revised standard, TB117-2013, had lower dust concentrations of harmful FRs, suggesting less FR was used in the furnishings.

\section{INTRODUCTION}

In 2013, California revised its primary furniture flammability standard, and it can be met without added flame retardant (FR) chemicals. ${ }^{1}$ Previous research has demonstrated that dust concentrations of FRs are influenced by furniture flammability standards that rely on added FR chemicals. ${ }^{2,3}$ Therefore, FR dust concentrations are expected to be lower in spaces with furniture adhering to the updated standard.

California's furniture flammability standards are de facto national standards in the U.S. Prior to 2013, FR chemicals were added to foam in upholstered furniture to meet a California performance-based standard known as Technical Bulletin 117 (TB117). ${ }^{4}$ California's revision of TB117, called TB117-2013, does not rely on added FRs, although it does not preclude their use. The new standard was phased in during 2014 and applied to all residential furniture sold in California starting January 1, 2015. As a result, it is possible for spaces furnished in 2014 and later in California, and therefore most other places in the U.S., to contain furniture meeting TB1172013. Some places that reference California standards later changed their fire codes to reflect the update. ${ }^{5,6}$ Research has found that FR levels were higher in Californians' blood and house dust compared to levels found in other states, presumably due to California's earlier and longer enforcement of TB117.

Received: June 18, 2020

Revised: July 23, 2020

Accepted: July 24, 2020

Published: September 3, 2020

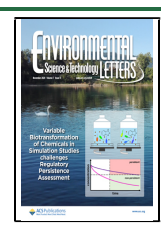


Separately, in 2019, California repealed an outdated and more severe standard called Technical Bulletin 133 (TB133) that applied to furniture in public spaces, ${ }^{7}$ which was met with high levels of FRs. ${ }^{2,8}$ We previously showed that some FR dust concentrations were higher in college dormitories that met TB133 compared to dormitories that met TB117. ${ }^{2}$

Fire safety scientists have questioned the efficacy of FR use in furniture, and research has shown significant health risks associated with FR exposures. ${ }^{8-10}$ Certain polybrominated diphenyl ethers (PBDEs), BDE 47 in particular, alter neurodevelopment in children, leading to decreased IQ. ${ }^{11,12}$ They were also found to be associated with higher risk of thyroid disease among women, with stronger effects in postmenopausal women. ${ }^{13}$ Studies have found many halogenated organophosphate flame retardants (OPFRs) to be neurotoxic, toxic to development and reproduction, and carcinogenic. ${ }^{14}$ Tris(1,3-dichloro-isopropyl) phosphate (TDCIPP) was removed from children's pajamas in 1978 because it is mutagenic, ${ }^{15,16}$ but it remained in wide use, alongside other chlorinated OPFRs, such as tris(2-chloroethyl) phosphate (TCEP), which has carcinogenicity concerns. ${ }^{17}$ Hexabromocyclododecane (HBCDD), which was widely used in extruded polystyrene insulation, is considered persistent, bioaccumulative, and toxic (PBT). ${ }^{18}$

We sought to evaluate whether FR concentrations are lower in spaces with furniture complying with the newer standard (TB117-2013) compared to the older standards (TB117 and TB133). We used data collected from nonresidential spaces on college campuses as these spaces are institutionally managed, minimizing variability in the standards used in the space, and typically densely furnished, increasing the FR load. We compared FR concentrations in dust samples collected from classrooms and lecture halls from four U.S. colleges in New England that adhere to TB117, TB133, and TB117-2013, adjusting for room characteristics (e.g., carpeting, number of upholstered furniture pieces). We also evaluated the FR composition of the dust. Previous work on FRs associated with TB117-2013 found that daycares that replaced TB117 nap mats with TB117-2013 nap mats had reductions of dust levels of bis(2-ethylhexyl)-3,4,5,6-tetrabromophthalate (BEHTEBP), 2-ethylhexyl-2,3,4,5-tetrabromobenzoate (EH-TBB), tris(4-butylphenyl) phosphate (TBPP), and TDCIPP. ${ }^{19}$ This study is the first evaluation of the impact of TB117-2013 furniture on FR concentrations in dust.

\section{MATERIALS AND METHODS}

Dust Sample Collection. Dust samples were collected from nonresidential spaces from four U.S. colleges in $\mathrm{New}$ England. Samples $(n=86)$ were collected from campuses in Spring 2015, Spring 2016, and Spring 2018. The temporal gap was due to difficulty identifying TB117-2013 spaces. We included a subset of samples $(n=27)$ from our previous analysis of FRs in college dormitories that were from nonresidential spaces. We collected a total of 86 dust samples from 43 TB133 spaces, 27 TB117 spaces, and 16 TB117-2013 spaces.

Dust was collected using previously published protocols by trained field staff using vacuum cleaners (Dyson, Inc., Chicago, IL) fitted with a custom aluminum crevice tool holding cellulose extraction thimbles $(19 \mathrm{~mm} \times 90 \mathrm{~mm}){ }^{2,20,21}$ In each space, staff lightly dragged the crevice tool over all room surfaces, including floors, furniture, desks, and window sills, for approximately $30 \mathrm{~min}$ to collect dust in thimbles, which were stored in certified glass jars (Environmental Sampling Supply, Dallas, TX) at less than $4{ }^{\circ} \mathrm{C}$ prior to shipment to the analytical laboratory.

Dust Sample Analysis. Chemical analysis targeted 43 chemicals, including 12 PBDE congeners, 19 other BFRs, 10 OPFRs, Dechlorane Plus (DP) isomers, and hexabromocyclododecane (HBCDD) isomers (Table S1). Prior to chemical analysis, samples were sieved $(<150 \mu \mathrm{m})$, weighed, and repackaged for shipment by Southwest Research Institute. Samples were analyzed in three different years, within months of collection.

Analysis comprised two sample preparation methods with three extracts per sample to target a range of FRs with different physicochemical properties. Briefly, samples were fractionated and either analyzed by gas chromatography-electron capture negative ion mass spectrometry (GC-ECNI/MS) and GCelectron impact (EI)/MS or by LC-MS/MS. More details about sample preparation and analysis can be found in Dodson et $\mathrm{al}^{2}$ and in the Supporting Information.

Quality Assurance/Quality Control. We used several $\mathrm{QA} / \mathrm{QC}$ measures to evaluate the accuracy and precision of our measurements and comparability between the data sets. Field or procedural blanks were analyzed in each batch. Results were blank-corrected by subtracting mean blank values from the raw FR values in the samples. Method limits of quantification (LOQs) were calculated as three times the standard deviation of procedural blank values divided by the amount of dust used for analysis. For compounds not detected in blanks, the LOQ was calculated based on a signal-to-noise ratio of 10:1. We replaced nondetect values with the limit of detection (LOD)*detection frequency for the chemical. See Supporting Information for additional details.

We evaluated accuracy using standard reference material (SRM) 2585 (Organic Contaminants in House Dust). For all analytes included in statistical analyses, the average relative difference was less than 27\% from the SRM2585 certified or indicative values (Figure SI1). We used SRM and field sample replicates to evaluate precision. Precision for SRM2585 replicates $(n=10)$ was within $30 \%$ for all analytes included in statistical analyses. One field sample from 2018 was split into triplicate samples, and precision was within $24 \%$ for analytes included in our analyses, except with higher values for decabromodiphenylethane (DBDPE), BDE 209, tetrabromobisphenol A (TBBPA), BDE 47, and TDCIPP (Table S1).

Additional Data Collection. Trained staff conducted visual inspections of sampling spaces, noting the number, type, and condition of upholstered furniture, flammability standard labels, and carpeting. We solicited information about the furnishings in the sampled spaces from campus administrators.

Data Analysis. We summarized concentrations by flammability standard using descriptive statistics. We prioritized 14 FRs (4 PBDEs, 6 brominated compounds, 3 chlorinated OPFRs, and one nonhalogenated OPFR) for statistical analyses based on their prevalence in this study (detected above the LOQ in at least $60 \%$ of samples) and previous research indicating their use in furniture and/or textiles. $^{22,23}$ Flame retardant uses in furniture and other products are summarized in Figure SI2.

To compare concentrations across spaces meeting different furniture flammability standards, we estimated linear regression models. To meet the normality assumption, we used natural log-transformed concentrations as the outcome. Our baseline model included dummy variables for TB133 and TB117 (with 

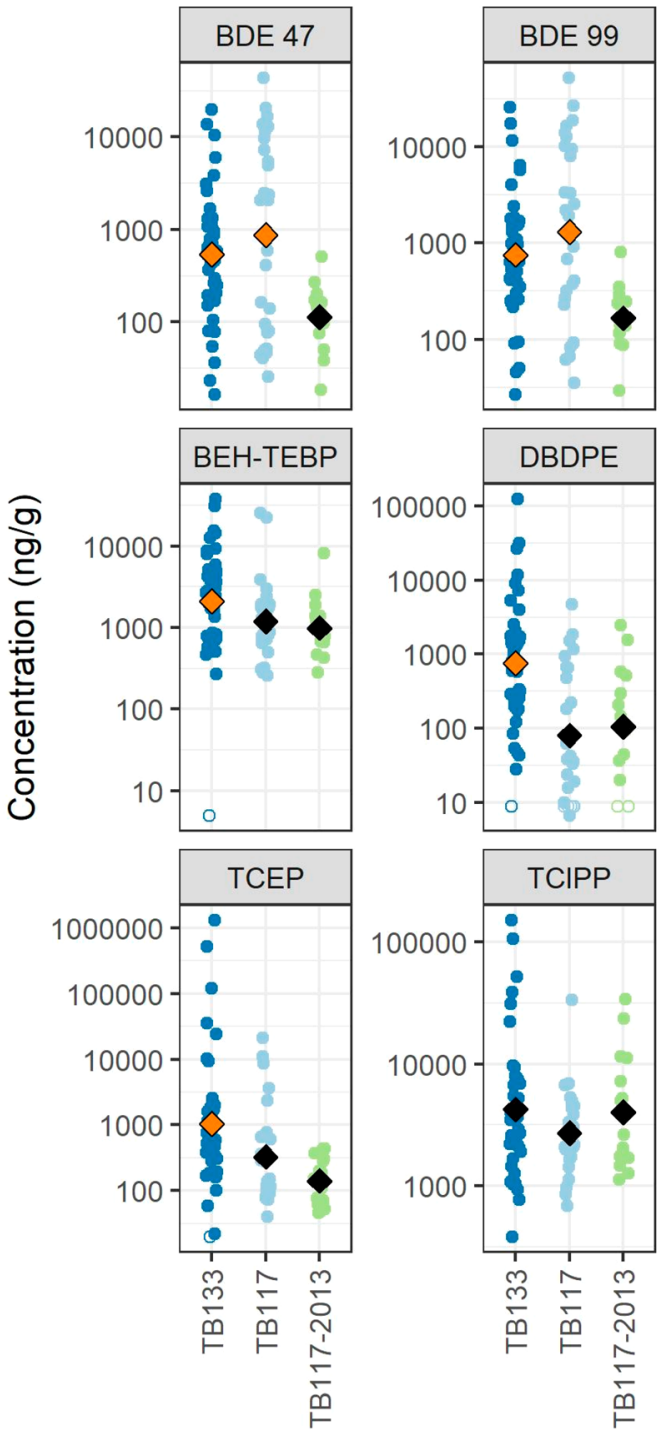
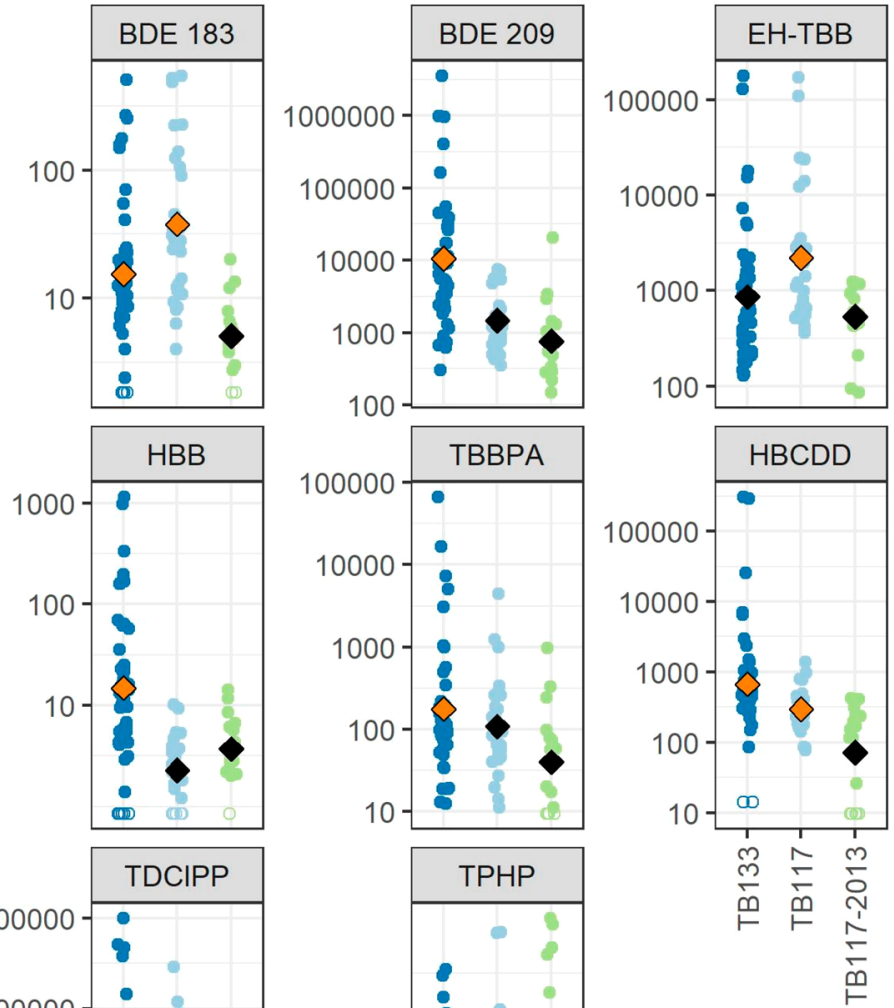

(n)

Flammability
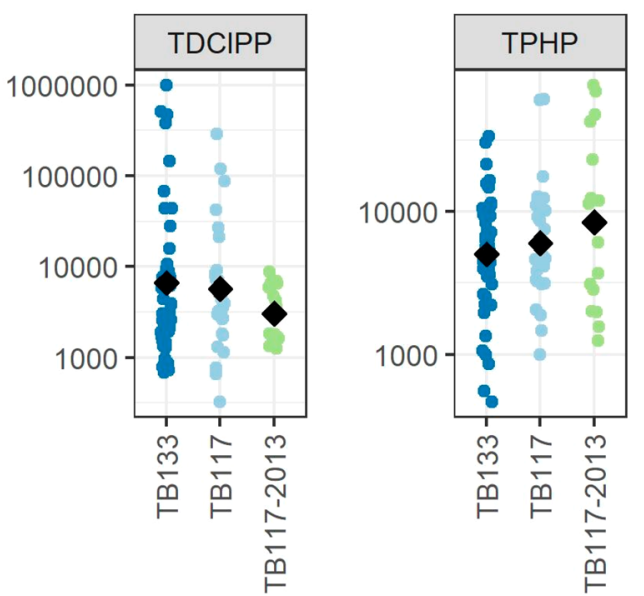
Standard

TB133

7 TB117-2013

Significantly Different than TB117-2013

$p>=0.05 \diamond p<0.05$

Figure 1. FR concentrations $(\mathrm{ng} / \mathrm{g})$ in spaces $(n=86)$ adhering to different furniture flammability standards. Estimated marginal means plotted as diamonds with color indicating statistically significant differences compared to TB117-2013 (baseline model). Nondetects are unfilled circles.

TB117-2013 the reference group) as explanatory variables. Separately, we ran adjusted models to increase the precision of our estimates, which included covariates assumed to be independently associated with the outcome: carpeting in at least half the room (dichotomous: yes/no) and number of upholstered furniture pieces. Information on carpeting was missing from 17 spaces and on upholstered furniture from 10 spaces (19 spaces missing data out of 86 ). Observations from these spaces were dropped from the adjusted models. To evaluate the effect of FR levels and standards in rooms furnished before 2005, when PentaBDE was phased out, we stratified our adjusted analysis by spaces furnished after 2004, noting that TB117-2013 spaces were never furnished before 2005. For all three models, significance was determined at alpha $=0.05$.

We compared the composition of priority FRs in dust across flammability standards. Because different FRs are likely used (or not used) to meet different standards, we expected the FR composition in dust to vary. Using geometric mean (GM) concentrations, we calculated the proportion of each FR to the total concentration (sum of all GMs). We tested for differences in proportions by standard using a three-sample test for equality of proportions.

Analyses were conducted in $\mathrm{R}$ (version 3.6.3; R Development Core Team).

\section{RESULTS AND DISCUSSION}

Dust Concentrations. We detected all 43 measured FRs (Table SI1). PBDEs were found consistently (detection frequencies: $>60 \%$ for all). Of the PBDEs, BDE 209 had the highest concentrations, with a maximum of $3,500,000 \mathrm{ng} / \mathrm{g}$ (or $3.5 \mathrm{mg} / \mathrm{g}$ ) and median of $2400 \mathrm{ng} / \mathrm{g}$. The brominated FRs in Firemaster550, a replacement mixture for PentaBDE, were found in nearly all samples along with DBDPE, used in similar applications as DecaBDE. OPFRs were found at the highest levels compared to other FR groups, with tris(2-butoxyethyl) 

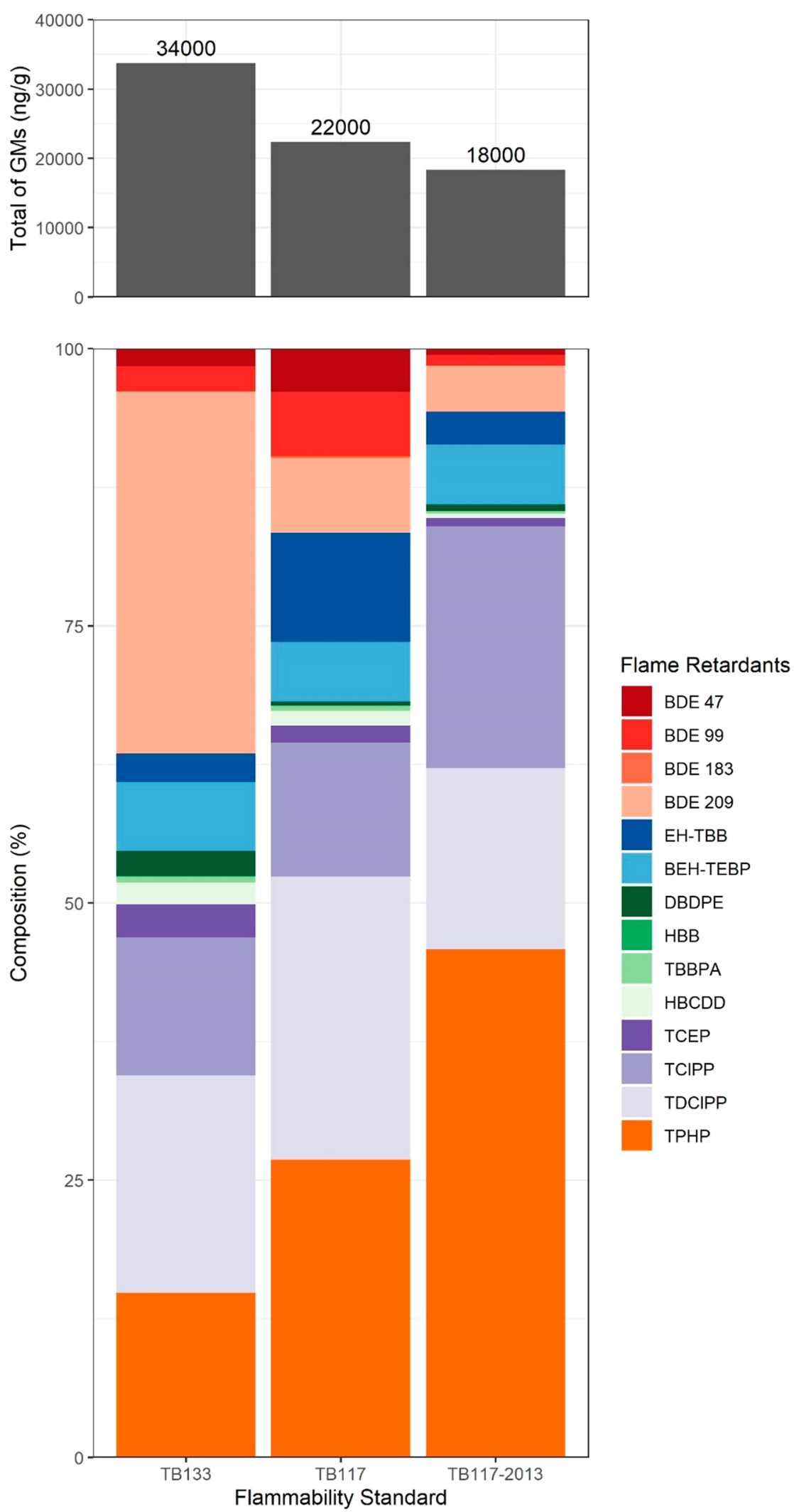

Figure 2. FR composition in spaces adhering to different furniture flammability standards. Proportions are GM of each chemical to sum of GMs for all chemicals (top bar graph).

phosphate (TBOEP) found at the highest median concentration of all FRs at 59,000 ng/g. Concentration distributions for all FRs were highly right skewed, with maxima up to 3000 times higher than the median (TCEP).
Median levels of priority FR concentrations were similar to our previous analysis of dormitories. ${ }^{2}$ Previously, we reported the highest dust concentrations of several FRs. Maximum concentrations of BDE 209, EH-TBB, DBDPE, TCEP, and 
TDCIPP were even higher in the current study. To our knowledge, these maxima, except for TDCIPP, are the highest levels measured in indoor dust in the U.S. Comparisons to literature values are listed in Table SI2.

Influence of Flammability Standards on Dust Concentrations. Most PBDE concentrations, including BDE 47 and BDE 99 (used in PentaBDE) and BDE 183 (used in OctaBDE), were significantly higher in TB133 and TB117 spaces compared to TB117-2013 spaces in the baseline model (Figure 1). PentaBDE and OctaBDE mixtures were used in furniture prior to their 2004 phase-out. $^{22,23}$ The persistent properties of PentaBDE and OctaBDE, or their presence in nonrenovated articles, may explain their high detection frequencies in TB117-2013 spaces. BDE 209 concentrations were significantly higher in TB133 spaces than TB117-2013 spaces. This is consistent with our previous study that observed higher BDE 209 levels in TB133 spaces than TB117 spaces. ${ }^{2}$ BDE 209 was likely used in textile back-coatings in furniture to meet TB133, ${ }^{24,25}$ and it was also used extensively in electronic casings. $^{26}$

Firemaster 550, which contains two brominated FRs, EHTBB and BEH-TEBP, along with TPHP, was introduced in 2004 to replace PentaBDE and OctaBDE. ${ }^{22,23}$ EH-TBB was significantly higher in TB117 spaces than TB117-2013 spaces. BEH-TEBP was used in other FR mixtures before the introduction of Firemaster 550, ${ }^{27}$ possibly explaining its significantly higher levels in TB133 spaces compared to TB117-2013 spaces. We observed no significant differences in TPHP concentrations by standard, likely because of its diverse uses (Figure SI2).

Concentrations of brominated FRs HBB, TBBPA, and DBDPE were significantly higher in TB133 spaces than TB117-2013 spaces. DBDPE is a replacement for BDE 209, so its higher levels in TB133 spaces are not unexpected. TBBPA is a widely used and nonrestricted FR, primarily in reactive and polymeric forms, ${ }^{14}$ while $\mathrm{HBB}$ is not widely used. However, dust levels may reflect past uses in TB133 spaces or different release rates of TBBPA used in reactive form.

HBCDD was significantly higher in TB133 and TB117 spaces than TB117-2013 spaces. We previously found significantly higher concentrations of HBCDD in dorm rooms meeting TB133 compared to TB117. HBCDD has been used in extruded polystyrene insulation boards, textiles, and electronics, ${ }^{28,29}$ and its use has been declining since its listing on the Stockholm Convention in 2013. ${ }^{18}$

Among the chlorinated OPFRs, only TCEP concentrations were significantly different by standard. TCEP was significantly higher in TB133 spaces than TB117-2013 spaces. TDCIPP levels were nonsignificantly lower in TB117-2013 spaces. There were no significant differences for TCIPP by standard, perhaps because it has many other uses besides furniture, such as plastics, rubber, and textiles (Figure SI2).

In the adjusted models the findings were similar, except for TCEP. TCEP concentrations were significantly higher in TB117 spaces compared to TB117-2013 in the adjusted model but not the baseline model, although the direction of the association in both models was the same (Table SI2). The difference is likely due to consistently lower levels of TCEP in TB117 spaces missing carpet information, thus making the TB117 comparison group appear elevated in the adjusted model.

Influence of Flammability Standards on Dust Concentrations after 2004. When we stratified our analysis to include only spaces furnished after 2004, we still observed that TB117-2013 spaces had significantly lower FR levels for BDE 99, BDE 183, and TCEP compared to both TB133 and TB117 spaces (Table SI3). However, we no longer observed significantly lower FR levels between TB133 spaces furnished after 2004 compared to TB117-2013 spaces for BDE 47, BEHTBEP, and DBDPE. Similarly, HBCDD concentrations were no longer significantly lower in TB117 spaces furnished after 2004 compared to TB117-2013 spaces. The smaller sample size (67 samples compared to 86 ) for the post-2004 furnished spaces likely reduced statistical power, causing some observations to become nonsignificant. BDE 209 concentrations were significantly higher in TB117 spaces furnished after 2004 than in TB117-2013 spaces. This could be due to an increase in BDE 209 use after 2004, before its scheduled phaseout in 2013 in the U.S. ${ }^{30}$

Dust Composition by Flammability Standard. The composition of FRs in dust varied by flammability standard (Figure 2). The proportion of PBDEs varied significantly by standard; PBDEs comprised approximately $36 \%$ of the FR concentrations of the dust in TB133 spaces, $17 \%$ of dust in TB117 spaces, and 6\% of dust in TB117-2013 spaces. Because all TB117-2013 spaces were renovated after the PentaBDE phase-out, this is consistent with FR use trends. BDE 209 comprised nearly $89 \%$ of the PBDEs in TB133 spaces and $40 \%$ in TB117 spaces, consistent with its use in furniture to meet TB133. The proportion of chlorinated OPFRs was relatively consistent $(38 \%-39 \%)$ in $\mathrm{TB} 133$ and $\mathrm{TB} 117$ spaces and slightly, yet significantly, lower in TB117-2013 spaces. Among chlorinated OPFRs, the proportion of TCIPP was highest in the TB117-2013 spaces (56\%). The proportion of TPHP, a nonchlorinated OPFR, was significantly highest in TB1172013 spaces. Both TCIPP and TPHP have other uses unrelated to furniture; one of the largest uses of TCIPP is in spray foam insulation. ${ }^{31}$

Limitations. This study evaluated the impact of TB1172013 on a broad range of FRs in university settings in the U.S., making it one of the first studies to evaluate the effect of the new standard on exposures. Because our data set included only 16 dust samples from two campuses with TB117-2013 spaces, we are not able to generalize our findings to all TB117-2013 spaces, and the small sample size is a limitation of our study. We relied on communications with campus administrators to understand flammability standard adherence, though we did not have information on whether FRs were used in the TB1172013 furniture. This may have created the possibility for misclassification of TB117-2013 spaces that may have had furniture with FRs. We did not have data on FRs or standards used in other components in each space, such as electronics or insulation, nor complete data on date of refurbishment of each space, cleaning practices, or age of the building, and these unaccounted-for factors may influence FR concentrations in the spaces.

Implications. This is the first study, to our knowledge, to demonstrate that FR dust concentrations are lower in spaces adhering to the newer furniture flammability standard TB1172013. The lower dust concentrations of FRs in TB117-2013 spaces suggest those spaces confer lower body burdens and associated health effects to occupants, compared to TB117 and TB133 spaces. More generally, this study adds to evidence that furniture flammability standards affect FR exposures via dust. When flammability standards for consumer products are developed or updated, potential exposure to and toxicity of 
FRs that could be used to meet such standards should be evaluated. It is also important to highlight that nonchemical methods, such as automatic sprinklers, smoke detectors, smoking bans, and use of inherently less flammable materials are important contributors to fire safety.

\section{ASSOCIATED CONTENT}

\section{SI Supporting Information}

The Supporting Information is available free of charge at https://pubs.acs.org/doi/10.1021/acs.estlett.0c00483.

Information as mentioned in the text (PDF)

\section{AUTHOR INFORMATION}

\section{Corresponding Author}

Kathryn M. Rodgers - Silent Spring Institute, Newton,

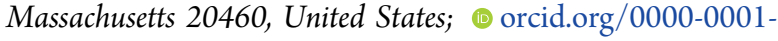
5879-2096; Phone: 617-332-4288; Email: rodgers@ silentspring.org

\section{Authors}

Adrian Covaci - Toxicological Centre, University of Antwerp, 2610 Wilrijk-Antwerp, Belgium; 으이이.org/0000-00030527-1136

Giulia Poma - Toxicological Centre, University of Antwerp, 2610 Wilrijk-Antwerp, Belgium; (o orcid.org/0000-00030597-2653

Kristin Knox - Silent Spring Institute, Newton, Massachusetts 20460, United States

Joseph G. Allen - Harvard T.H. Chan School of Public Health, Boston, Massachusetts 02215, United States; ㅇo이.org/ 0000-0003-2702-5550

Jose Cedeno-Laurent - Harvard T.H. Chan School of Public Health, Boston, Massachusetts 02215, United States

Ruthann A. Rudel - Silent Spring Institute, Newton, Massachusetts 20460, United States

Robin E. Dodson - Silent Spring Institute, Newton, Massachusetts 20460, United States; @ orcid.org/0000-00017356-9511

Complete contact information is available at:

https://pubs.acs.org/10.1021/acs.estlett.0c00483

\section{Notes}

The authors declare no competing financial interest.

\section{ACKNOWLEDGMENTS}

This work was supported by the John Merck Fund, the Fine Fund, the Hoffman Program on Chemicals and Health, and charitable donations to Silent Spring Institute. We thank the participating colleges and M. Dashko, L. Swetschinski, L. Borth, and K. Vilardi for assistance with sampling and C. Christia for help with the sample analysis.

\section{REFERENCES}

(1) State of California Technical Bulletin 117-2013: Requirements, Test Procedure, and Apparatus for Testing the Smolder Resistance of Materials Used in Upholstered Furniture; State of California, Department of Consumer Affairs, Bureau of Electronic \& Appliance Repair Home Furnishings \& Thermal Insulation: Sacramento, CA, 2013.

(2) Dodson, R. E.; Rodgers, K. M.; Carey, G.; Cedeno Laurent, J. G.; Covaci, A.; Poma, G.; Malarvannan, G.; Spengler, J. D.; Rudel, R. A.; Allen, J. G. Flame Retardant Chemicals in College Dormitories: Flammability Standards Influence Dust Concentrations. Environ. Sci. Technol. 2017, 51 (9), 4860-4869.
(3) Zota, A. R.; Rudel, R. A.; Morello-Frosch, R. A.; Brody, J. G. Elevated house dust and serum concentrations of PBDEs in California: Unintended consequences of furniture flammability standards? Environ. Sci. Technol. 2008, 42 (21), 8158-8164.

(4) State of California Technical Bulletin 117: Requirements, Test Procedure, and Apparatus for Testing the Flame Retardance of Resilient Filling Materials Used in Upholstered Furniture; State of California, Department of Consumer Affairs, Bureau of Electronic \& Appliance Repair Home Furnishings \& Thermal Insulation: North Highlands, CA, 2000.

(5) Massachusetts Comprehensive Fire Safety Code: 527 CMR 1.00; Massachusetts Department of Fire Services: Board of Fire Prevention Regulations, 2015.

(6) Regulation of Upholstered Furniture: BFD IX-10; Boston Fire Department, 2016

(7) Division 3 of Title 4 of the California Code of Regulation, Bureau of Electronic and Appliance Repair Home Furnishings; State of California, Office of Administrative Law, Bureau of Electronic and Appliance Repair Home Furnishings, and Thermal Insulation, 2019.

(8) Initial Statement of Reasons: Subject Matter of Proposed Regulations: Amendment of Flammability Standards; State of California, Bureau of Electronic and Appliance Repair, 2018.

(9) Babrauskas, V.; Blum, A.; Daley, R.; Birnbaum, L. Flame Retardants in Furniture Foam: Benefits and Risks. Fire Saf. Sci. 2011, $10,265-278$.

(10) Rodgers, K. M.; Swetschinski, L. R.; Dodson, R. E.; Alpert, H. R.; Fleming, J. M.; Rudel, R. A. Health Toll From Open Flame and Cigarette-Started Fires on Flame-Retardant Furniture in Massachusetts, 2003-2016. Am. J. Public Health 2019, 109 (9), 1205-1211.

(11) Dorman, D. C.; Chiu, W.; Hales, B. F.; Hauser, R.; Johnson, K. J.; Mantus, E.; Martel, S.; Robinson, K. A.; Rooney, A. A.; Rudel, R.; Sathyanarayana, S.; Schantz, S. L.; Waters, K. M. Polybrominated diphenyl ether (PBDE) neurotoxicity: a systematic review and metaanalysis of animal evidence. J. Toxicol. Environ. Health, Part B 2018, 21 (4), 269-289.

(12) Lam, J.; Lanphear, B. P.; Bellinger, D.; Axelrad, D. A.; McPartland, J.; Sutton, P.; Davidson, L.; Daniels, N.; Sen, S.; Woodruff, T. J. Developmental PBDE Exposure and IQ/ADHD in Childhood: A Systematic Review and Meta-analysis. Environ. Health Perspect. 2017, 125 (8), 086001.

(13) Allen, J. G.; Gale, S.; Zoeller, R. T.; Spengler, J. D.; Birnbaum, L.; McNeely, E. PBDE flame retardants, thyroid disease, and menopausal status in U.S. women. Environ. Health 2016, 15 (1), 60.

(14) Blum, A.; Behl, M.; Birnbaum, L. S.; Diamond, M. L.; Phillips, A.; Singla, V.; Sipes, N. S.; Stapleton, H. M.; Venier, M. Organophosphate Ester Flame Retardants: Are They a Regrettable Substitution for Polybrominated Diphenyl Ethers? Environ. Sci. Technol. Lett. 2019, 6 (11), 638-649.

(15) Gold, M. D.; Blum, A.; Ames, B. N. Another flame retardant, tris-(1,3-dichloro-2-propyl)-phosphate, and its expected metabolites are mutagens. Science 1978, 200 (4343), 785-7.

(16) Sanders, H. J. Flame Retardants: Government Regulations and Public Emphasis on Safety Provide the Impetus for an Expanding industry. Chem. Eng. News 1978, 56 (17), 22-36, DOI: 10.1021/cenv056n017.p022.

(17) Chemicals Considered or Listed Under Proposition 65: Tris(2chloroethyl) Phosphate. https://oehha.ca.gov/proposition-65/ chemicals/tris2-chloroethyl-phosphate (accessed July 23, 2020).

(18) The New POPs under the Stockholm Convention. http://chm. pops.int/TheConvention/ThePOPs/TheNewPOPs/tabid/2511/ Default.aspx (accessed July 23, 2020),

(19) Stubbings, W. A.; Schreder, E. D.; Thomas, M. B.; Romanak, K.; Venier, M.; Salamova, A. Exposure to brominated and organophosphate ester flame retardants in U.S. childcare environments: Effect of removal of flame-retarded nap mats on indoor levels. Environ. Pollut. 2018, 238, 1056-1068.

(20) Rudel, R. A.; Brody, J. G.; Spengler, J. C.; Vallarino, J.; Geno, P. W.; Sun, G.; Yau, A. Identification of selected hormonally active agents and animal mammary carcinogens in commercial and 
residential air and dust samples. J. Air Waste Manage. Assoc. 2001, 51 (4), 499-513.

(21) Rudel, R. A.; Camann, D. E.; Spengler, J. D.; Korn, L. R.; Brody, J. G. Phthalates, alkylphenols, pesticides, polybrominated diphenyl ethers, and other endocrine-disrupting compounds in indoor air and dust. Environ. Sci. Technol. 2003, 37 (20), 4543-53.

(22) Dodson, R. E.; Perovich, L. J.; Covaci, A.; Van den Eede, N.; Ionas, A. C.; Dirtu, A. C.; Brody, J. G.; Rudel, R. A. After the PBDE phase-out: a broad suite of flame retardants in repeat house dust samples from California. Environ. Sci. Technol. 2012, 46 (24), 1305666.

(23) Stapleton, H. M.; Sharma, S.; Getzinger, G.; Ferguson, P. L.; Gabriel, M.; Webster, T. F.; Blum, A. Novel and high volume use flame retardants in US couches reflective of the 2005 PentaBDE phase out. Environ. Sci. Technol. 2012, 46 (24), 13432-9.

(24) Decabromodiphenylether: An Investigation of Non-Halogen Substitutes in Electronic Enclosure and Textile Applications; Lowell Center for Sustainable Production, University of Massachusetts Lowell: Lowell, MA, 2005.

(25) Ghanem, R.; Delmani, F.-A. Kinetics of thermal and photolytic degradation of decabromodiphenyl ether (BDE 209) in backcoated textile samples. J. Anal. Appl. Pyrolysis 2012, 98, 79-85.

(26) Abbasi, G.; Buser, A. M.; Soehl, A.; Murray, M. W.; Diamond, M. L. Stocks and flows of PBDEs in products from use to waste in the U.S. and Canada from 1970 to 2020. Environ. Sci. Technol. 2015, 49 (3), 1521-8.

(27) Davis, E. F.; Stapleton, H. M. Photodegradation pathways of nonabrominated diphenyl ethers, 2-ethylhexyltetrabromobenzoate and $\operatorname{di}(2$-ethylhexyl)tetrabromophthalate: identifying potential markers of photodegradation. Environ. Sci. Technol. 2009, 43 (15), 5739-46.

(28) Covaci, A.; Gerecke, A. C.; Law, R. J.; Voorspoels, S.; Kohler, M.; Heeb, N. V.; Leslie, H.; Allchin, C. R.; De Boer, J. Hexabromocyclododecanes (HBCDs) in the environment and humans: a review. Environ. Sci. Technol. 2006, 40 (12), 3679-88.

(29) Company Strategies. ICL-IP closes HBCD flame retardant production line. Additives for Polymers 2015, 2015 (9), 7-8.

(30) Hess, G., Industry To Phase Out decaBDE. Chem. Eng. News. https://cen.acs.org/articles/87/web/2009/12/Industry-PhasedecaBDE.html (July 23, 2020).

(31) Bello, A.; Carignan, C. C.; Xue, Y.; Stapleton, H. M.; Bello, D. Exposure to organophosphate flame retardants in spray polyurethane foam applicators: Role of dermal exposure. Environ. Int. 2018, 113, $55-65$. 